\title{
Rapidly progressive relapsing sclerosing cholangitis following surgery for pancreatic pseudotumor
}

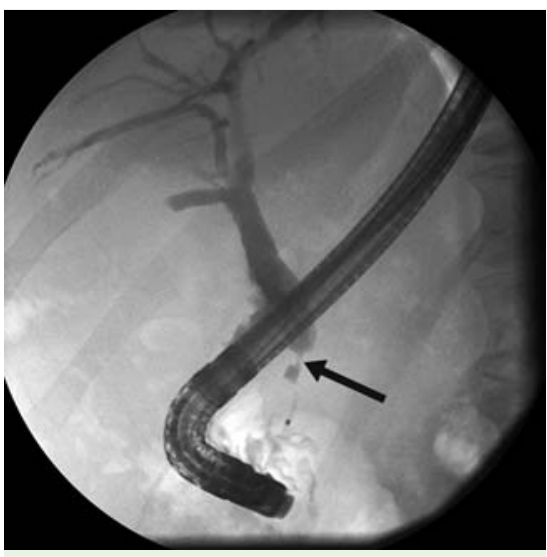

Fig. 1 Endoscopic retrograde cholangiogram demonstrating a short, tight stricture (arrow) in the distal common bile duct with prestenotic dilatation.

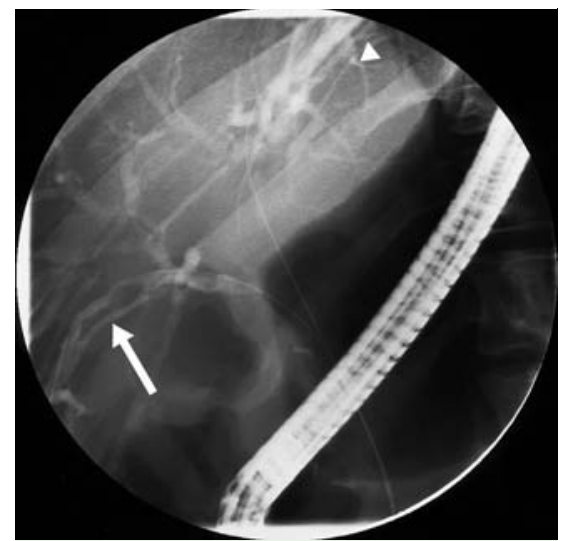

Fig. 2 Endoscopic retrograde cholangiogram demonstrating diffuse stricturing (arrowhead) and dilatation (arrow) of intrahepatic radicles.

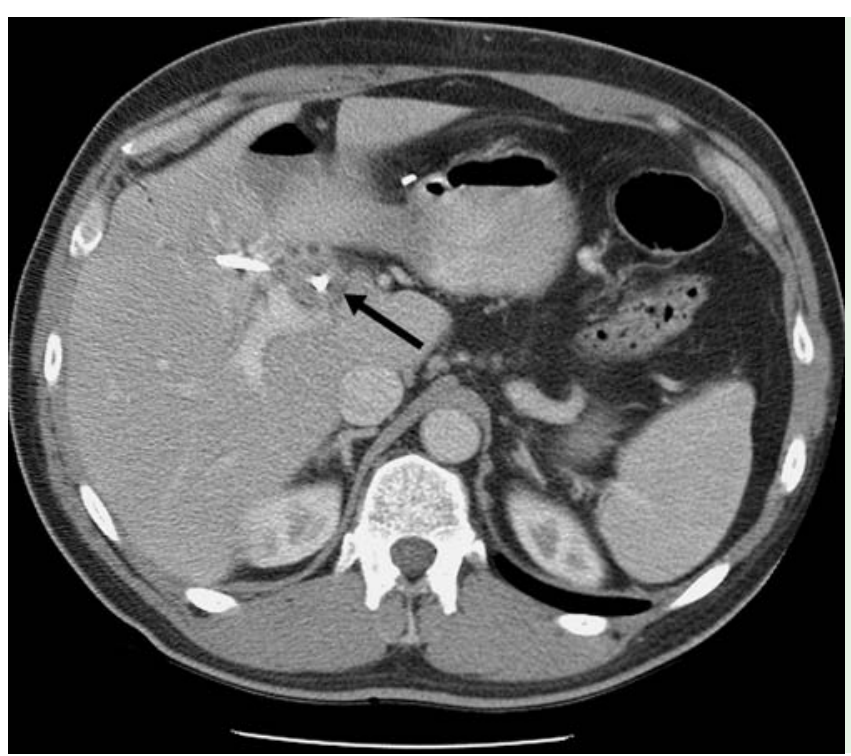

A 52-year-old man presented with painless jaundice and weight loss. A computed tomography (CT) scan of the abdomen revealed an inflammatory mass in the pancreatic head. Endoscopic retrograde cholangiopancreatography (ERCP) demonstrated a double duct sign ( Fig. 1), and a biliary stent was placed. Brush cytology was negative and percutaneous biopsy showed inflammatory changes. Laparotomy confirmed a large inflammatory mass in the pancreatic head, and a cholecystojejunostomy was carried out. Several months later, the patient developed recurrent jaundice and ERCP showed new diffuse strictures involving
Fig. 3 CT scan of the abdomen showing concentric thickening of the common hepatic duct (arrow) suggesting marked inflammation.

the intra- and extrahepatic biliary tree ( Fig. 2). CT abdomen revealed concentric thickening of the common bile duct (CBD) with enlarged periportal nodes ( Fig.3), and endoscopic ultrasound with fine-needle aspiration biopsy of the pancreatic head and lymph nodes was benign. A liver biopsy showed bile duct inflammation and marked cholestasis, and ultrasound revealed patent vasculature. Colonoscopy as well as autoimmune serology and IgG4 levels were normal.

A diagnosis of secondary autoimmune pancreatitis associated sclerosing cholangitis (AIP-SC) was considered. The patient was prescribed steroids and methotrex-

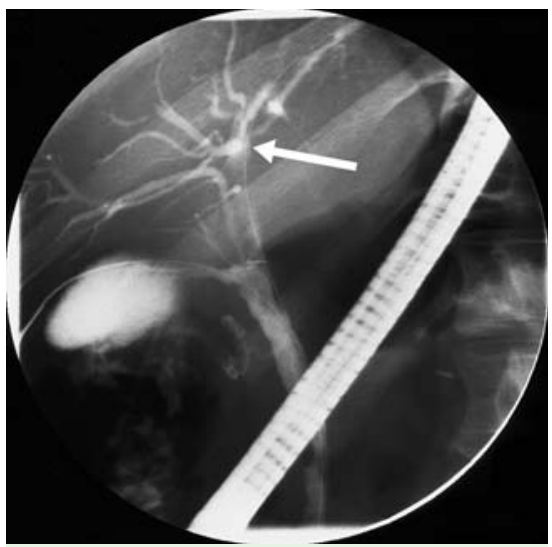

Fig. 4 Endoscopic retrograde cholangiogram demonstrating marked improvement in the diffuse stricturing and dilatation of branches of intrahepatic biliary radicles (seen in $\bullet$ Fig. 2).

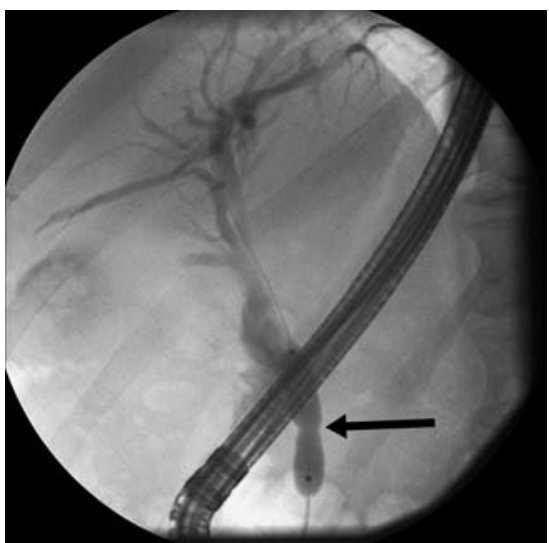

Fig. 5 Endoscopic retrograde cholangiogram demonstrating balloon dilatation (arrow) of a distal bile duct stricture.

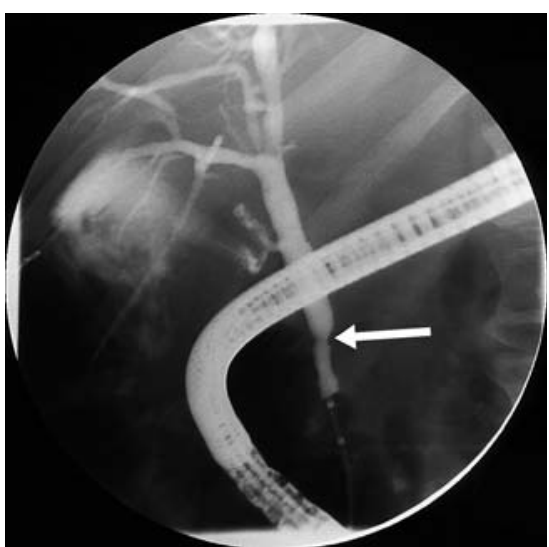

Fig. 6 Endoscopic retrograde cholangiogram demonstrating marked improvement in the distal bile duct stricture (arrow) after dilation and several months of immunosuppression. 
ate. Several months later ERCP showed marked improvement of the biliary tree ( $\bullet$ Fig. 4). Over the next 5 years, the patient was maintained on azathioprine $100 \mathrm{mg}$ daily, with normal liver enzymes. On tapering the azathioprine to $50 \mathrm{mg}$ daily, he developed acute cholangitis. ERCP showed stricturing of the extrahepatic biliary tree requiring balloon dilation and stenting ( Fig.5). The patient was restarted on a prednisone taper and azathioprine $75 \mathrm{mg}$ daily, with marked improvement seen on a cholangiogram taken 3 months later ( $\mathbf{F i g} \cdot \mathbf{6}$ ). The patient is currently well with normal liver enzymes and is taking $75 \mathrm{mg}$ azathioprine daily.

Clinicians should be aware that AIP-SC can mimic pancreatic cancer. In addition, sclerosing cholangitis can complicate AIP, particularly after biliary bypass surgery
[1,2]. Until the etiology, pathogenesis, and natural history have been defined more precisely, no definite recommendations with respect to medical therapy can be made. However, treatment with corticosteroids and/or other immunosuppressive therapy can be effective in patients presenting with this entity [3].

Endoscopy_UCTN_Code_CCL_1AZ_2AZ

Endoscopy_UCTN_Code_CCL_1AZ_2AG

\section{I. El Hajj ${ }^{1}$, J. Ahmad², A. Slivka \\ 1 Department of Internal Medicine, University of Pittsburgh, Pittsburgh, Pennsylvania, USA \\ 2 Division of Gastroenterology, Hepatology and Nutrition, University of Pittsburgh, Pittsburgh, Pennsylvania, USA}

\section{References}

1 Stathopoulos G, Nourmand AD, Blackstone M et al. Rapidly progressive sclerosing cholangitis following survival treatment of pancreatic pseudotumor. J Clin Gastroenterol 1995; $21: 143-148$

2 Beachley MC, Lankau CA. Sclerosing cholangitis simulating periampullary carcinoma: case report. Milit Med 1976; 141: 475- 476

3 Toosi MN, Heathcote J. Pancreatic pseudotumor with sclerosing pancreato-cholangitis: is this a systemic disease? Am J Gastroenterol 2004; 99: 377-382

\section{Bibliography}

DOI $10.1055 / \mathrm{s}-0029-1214802$

Endoscopy 2009; 41: E246-E247

(c) Georg Thieme Verlag KG Stuttgart · New York . ISSN 0013-726X

\section{Corresponding author}

\section{J. Ahmad, MD, MRCP (UK)}

Division of Gastroenterology, Hepatology and Nutrition

University of Pittsburgh

Pittsburgh, PA 15213

USA

Fax: +1-412-647-9268

ahmadj@msx.upmc.edu 